\title{
Overt Primary Hypothyroidism in an Industrial Area in São Paulo, Brazil: The Impact of Public Disclosure
}

\author{
Maria Angela Zaccarelli-Marino ${ }^{1, *}$, Carmen Diva Saldiva André ${ }^{2}$ and Julio M. Singer ${ }^{2}$ \\ 1 Internal Medicine Department, Endocrinology Service, ABC Medical School Foundation, \\ Santo André 09060-650, Brazil \\ 2 Department of Statistics, Institute of Mathematics and Statistics, University of São Paulo, \\ São Paulo 05508-090, Brazil; carmensaldiva@gmail.com (C.D.S.A.); jmsinger@ime.usp.br (J.M.S.) \\ * Correspondence: mangelazaccarelli@yahoo.com.br; Tel.: +55-11-3824-9060
}

Academic Editor: William A. Toscano

Received: 13 September 2016; Accepted: 17 November 2016; Published: 22 November 2016

\begin{abstract}
Background: Primary hypothyroidism (PH) is the most common thyroid pathology. Purpose: to evaluate the impact of public disclosure of an unexpected number of $\mathrm{PH}$ cases on the frequency of patients seeking medical evaluation for endocrinological diseases. Methods: data on 6306 subjects (3356 living in the surroundings of a petrochemical complex and 2950 in a control region) were collected over a 15-year time span. Thyroid function was determined by serum levels of triiodothyronine, thyroxine, free thyroxine and thyrotrophin. Antithyroglobulin and antithyroperoxidase antibodies and sonographic scans of the thyroid were performed in all patients. The data were analyzed via log-linear models to compute odds and odds ratios. Results: An increasing trend in the odds of $\mathrm{PH}$ was detected along the observation period with greater slope in the study region than in the control region. The odds of $\mathrm{PH}$ in the post-disclosure period (2002 to 2004) are greater than the corresponding ones in the pre-disclosure period (1989 to 2001). Conclusions: This study shows that living in the surroundings of a petrochemical complex may be an important risk factor for $\mathrm{PH}$ for both adults and children. Furthermore, public disclosure of such risk factor contributes to the awareness of the problem and to the possibility of an early diagnosis.
\end{abstract}

Keywords: autoimmune thyroiditis; industrial environment; petroleum byproducts; primary hypothyroidism

\section{Introduction}

In 1989, a patient diagnosed with overt primary hypothyroidism $(\mathrm{PH})$, originated from a chronic autoimmune thyroiditis (CAT), called the attention of the first author of this study because he was a 37 year old male, working in a chemical industry and known to wash his hands with trichloroethylene, a volatile organic compound still used in industry as a degreasing agent. It is well known that trichloroethylene is highly toxic and considered as an important water and soil pollutant [1]. In adults, hypothyroidism can generate alterations of cardiac and cognitive functions, myxedema, hypercholesterolemia and incapacity to work or to lead a healthy family life [2-5]. In children, it may also have deleterious effects on growth, school performance and pubertal development. Adequate treatment leads to normal growth, puberty and normal final height $[3,5,6]$. Vanderpump et al. [7] emphasized that the cause of hypothyroidism is variable and depends on geographic and environmental factors as well as on genetic characteristics of the population and on age of disease onset.

Primary hypothyroidism is the most common thyroid pathology [8] and among other autoimmune thyroid diseases (AITD), CAT has been diagnosed with increased frequency in recent years $[7,9]$. In iodine sufficient regions, the major cause of PH is CAT [10]. According to Vanderpump et al. [7], 
patients with positive antithyroid antibodies are highly likely to develop hypothyroidism. These authors showed that $55 \%$ of the patients with elevated thyrotrophin (TSH) and positive antithyroid antibodies develop hypothyroidism in contrast to $33 \%$ of the patients who have only elevated TSH with negative antithyroid antibodies.

Benvenga and Trimarchi [11] reported that Hashimoto's thyroiditis (HT) has become 10 times more common than it was since the early 1990s with males being relatively more represented; they also showed that only environmental changes, as opposed to genetic changes, can account for such alterations in the presentation of HT. Rizzo et al. [12] also mention that only environmental modifications can explain the great increase in the annual frequency of HT that occurred in such a relatively short period of time.

According to Gilbert et al. [13], certain chemical agents like trichloroethylene may induce an autoimmune response in rats. These authors conjecture that suppression of immune responses in rodents may be predictive of a similar response in humans and that there is a relationship between immune suppression following developmental exposure to toxicants and enhanced risk of autoimmune or neoplastic disease [14]. Nineteen years before, Bahn et al. [15] had already observed an increased incidence of antimicrosomal thyroid antibodies and hypothyroidism in male factory workers exposed to other chemical agents, like polyhalogenated biphenyls (PBB) and polyhalogenated biphenyl oxides. Thirty years later, Brent [16] showed that environmental exposure to a series of chemicals, ranging from perchlorate to polychlorinated biphenols may affect thyroid function. This author concluded that most of these agents are associated with reduced thyroid hormone levels or impaired thyroid action and that environmental exposure to such agents induce an increased risk of autoimmune thyroid disease. Other authors [17] observed that organic pollutants such as polyaromatic hydrocarbons are associated with goiter and thyroid disease. On the other hand, Yang et al. [18] and Neuberger et al. [19] showed that cancer prevalence is higher for individuals living in areas surrounding plants that manufacture petroleum byproducts.

In 2002, the large number of cases of PH originated from CAT detected in patients seeking medical care in a densely populated area in the vicinity of a petrochemical complex was communicated by this first author to the Municipal and State Public Health Services and to the National Health Foundation (FUNASA) and was publicly disclosed. The frequency of patients with the same diagnosis increased between 2002 and 2004.

The objective of this study is to evaluate the impact of public disclosure of an unexpected number of $\mathrm{PH}$ on the frequency of patients seeking medical evaluation for endocrinological diseases. This is accomplished by comparing the odds of occurrence of $\mathrm{PH}$ in children and adults of both sexes living in the surroundings of a petrochemical complex seeking medical care with the corresponding odds for a population living in the vicinity of a steel producing industrial complex before and after the notification of the abnormal number of cases to public health authorities in 2002.

The data were collected over a 15-year time span, from 1989 to 2004 in two regions. The first (Region A), located on the boundary of the municipalities of Santo André, Mauá and São Paulo, state of São Paulo (SP), Brazil, consists of a densely populated area of 125 ha in the vicinity of large industrial plants that manufacture petroleum byproducts including polyethylene and polypropylene from naphtha distillation as well as various intermediate substances that are used as raw materials for manufacturing other products. The second (Region B) is a steel producing industrial area located on the boundary of the municipalities of Santo André, São Bernardo do Campo and São Caetano do Sul, $\mathrm{SP}$, Brazil, about $8.5 \mathrm{~km}$ away from Region A. No plants that manufacture petroleum byproducts are located in this region, treated as a control region in this study. The state environmental agency (CETESB) has a continuous air quality monitoring station in this area, where only the levels of particulate matter $\left(\mathrm{PM}_{10}\right)$ and ozone $\left(\mathrm{O}_{3}\right)$ are recorded. This study is a sequel to a survey about CAT in industrial areas in Brazil [20]. 


\section{Methods}

We compare two periods: the first consisting of 12 years (1989 to 2001), when the patients living in Region A spontaneously searched an endocrinology clinic located in Santo André, SP, Brazil and the second consisting of a 3 year period (2002 to 2004), starting after the first author notified the Epidemiological Surveillance Center (ESC) of the Department of Health of the State of São Paulo regarding the excessive number of $\mathrm{PH}$ observed in her endocrinology clinic.

\subsection{Ethical Statement}

This research was approved by the Committee of Ethics in Research of the Medical School of the ABC Foundation, SP, Brazil and registered under number 284/2007. The objectives and methods of this study were clearly stated to all patients or to parents in the case of children. All patients agreed to participate in this study.

\subsection{Subjects}

The 6306 subjects (3356 in Region A and 2950 in Region B) included in the study were selected from patients seeking medical attention and general endocrinological evaluation at an endocrinology clinic located in Santo André, SP, Brazil, run by the first author (Maria Angela Zaccarelli-Marino). Clinical history and physical examination including weight and height measurements, conducted by Maria Angela Zaccarelli-Marino, were performed in all 6306 patients selected for this study. Patients aged 18 or more were considered as adults and those aged 17 or less, as children. Only patients living in the same region for 10 years or more were included in the study. Furthermore, controls (patients from Region B) were matched with those from Region A according to social and educational status. Patients taking medications that could interfere with the outcome, including amiodarone, lithium carbonate, iodine and interferon, as well as those with hyperthyroidism, malignant nodules, previous thyroid treatment with radioiodine or radiotherapy of the chest or neck, primary hyperthyroidism of autoimmune origin (antibody anti-TSHR positive) were excluded from the study. Patients that showed nodular goiter, with nodules greater than $1 \mathrm{~cm}$, were referred for fine needle aspiration cytology, and those diagnosed with carcinoma were referred to surgery and excluded from the study. Employees in the chemical industries or those connected to agriculture in contact with pesticides were excluded from the study.

\subsection{Sample Collection}

Blood samples were collected, at a private laboratory (Fleming Medicina Diagnóstica) in the municipality of Santo André, SP. All patients spontaneously came to the laboratory, in the morning after $8 \mathrm{~h}$ of fasting. The children came accompanied by their parents or responsible ones. The blood samples were obtained by standard techniques. The collected blood was placed in adequate tubes and analyzed by standard procedures. Dosages of triiodothyronine (T3), thyroxine (T4), free thyroxine (FT4), thyrotrophin (TSH), antithyroglobulin antibody (A-Tg) and A-TPO (antithyroperoxidase antibody) were performed at the same laboratory using chemiluminescence (closed system, Immulite, DPC-MedLab, Los Angeles, CA, USA) or electrochemiluminescence (Ellecsys, Roche, Basel, Switzerland).

\subsection{Thyroid Hormones Measurement}

Thyroid function was determined by basal serum hormone levels of total T3, total T4, FT4 and TSH, obtained by chemiluminescence and electrochemiluminescence. The levels of FT4 were obtained only for patients examined after 1994.

Serum levels of A-Tg were obtained by fluoroimmunoassay and considered positive above $40 \mathrm{U} / \mathrm{mL}$ or by a chemiluminescence technique (also considered positive above $40 \mathrm{IU} / \mathrm{mL}$ ). Serum levels of A-TPO were obtained by radioimmunoassay (considered positive above $60 \mathrm{U} / \mathrm{mL}$ ) or by a chemiluminescence technique (considered positive above $35 \mathrm{IU} / \mathrm{mL}$ ). 


\subsection{Sonographic Scan}

Sonographic scans of the thyroid gland were performed by the same physicians with ample experience in image diagnosis (DISA) in the municipality of Santo André, SP using echography with a high resolution multi-frequency linear transducer $(7.5 \mathrm{MHz}$ and $10 \mathrm{MHz})$. Scans that showed homogeneous echotexture and a thyroid volume (ThV) between 6.0 and $17.1 \mathrm{~cm}^{3}$ were considered normal.

CAT was diagnosed in patients who were positive for antibodies to thyroglobulin and to thyroperoxidase and who showed heterogeneous texture and marked hypoechogenicity in the sonographic scans of their thyroid glands. Tests for A-Tg and A-TPO were performed because in iodine sufficient regions, CAT is the major cause of $\mathrm{PH}$ [10]. Iodine sufficiency for Region A was demonstrated in previous studies [21-23]. All patients selected for this study were diagnosed with CAT and all patients were positive for antibodies to thyroglobulin and to thyroperoxidase.

Overt PH was diagnosed when signs and clinical symptoms were present along with low total T4 (chemiluminescence, with normal values for children and adolescents between 6.0-13.5 $\mu \mathrm{g} / \mathrm{dL}$ and adults between $4.5-12.5 \mu \mathrm{g} / \mathrm{dL}$ or electrochemiluminescence, with normal values for children and adolescents

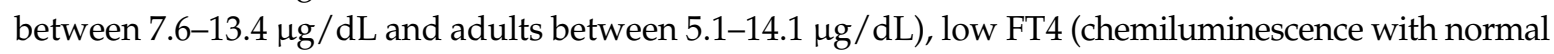
values for children, adolescents and adults between $0.8-1.9 \mathrm{ng} / 100 \mathrm{~mL}$ or electrochemiluminescence with normal values for children and adolescents between 1.1-1.8 ng/dL and adults between 0.9-1.7 ng/dL), $\mathrm{TSH} \geq 10 \mu \mathrm{IU} / \mathrm{mL}$ [9] (chemiluminescence with normal values for children, adolescents and adults between $0.4-4.0 \mu \mathrm{IU} / \mathrm{mL}$ or electrochemiluminescence with normal values for children, adolescents and adults between $0.2-8.0 \mu \mathrm{IU} / \mathrm{mL}$ ) and low total T3 (chemiluminescence with normal values for children, adolescents and adults between $70-170 \mathrm{ng} / \mathrm{dL}$ or electrochemiluminescence with normal values for children and adolescents between 80-260 ng/dL and adults between 80-200 ng/dL). All patients diagnosed with $\mathrm{PH}$ in this study have been treated with sodium levothyroxin.

\subsection{Statistical Analysis}

Initially, the odds of $\mathrm{PH}$ for each combination of the levels of age and sex in regions A and B were estimated in (approximately) three year periods starting in 1989; corresponding 95\% confidence intervals were also constructed. The same technique was applied to estimate the odds ratio of $\mathrm{PH}$ between the two periods of interest (after public disclosure (2002 to 2004) and before public disclosure (1989 to 2001)) for each region, age and sex. Similarly, the odds ratio for PH between the two regions (A and B) in each period (before and after public disclosure) for each age and sex was also computed.

The confidence interval limits for the odds or for the odds ratios were obtained by exponentiation of the corresponding limits of confidence intervals for their logarithms to achieve a better approximation by the Gaussian distribution. The odds of PH for the entire period 1989 to 2001 were computed as the geometric mean of the corresponding triennial odds. Wald chi-squared tests were used to detect significant odds ratios of $\mathrm{PH}$ between periods within regions or regions within periods. Details may be obtained in Agresti [24], for example. Computations were performed via the log-linear functions in the ACD (Analysis of Categorical Data) library available in the R (R Foundation for Statistical Computing, Vienna, Austria) statistical analysis package [25] and the codes may be obtained from the authors upon request.

\section{Results}

The percentage of patients with PH classified by sex, age and region and grouped in periods of approximately three years (to facilitate comparison of pre and post disclosure periods) are displayed in Table 1. 
Table 1. Percentage of patients with primary hypothyroidism $(\mathrm{PH})$ in regions $\mathrm{A}$ and $\mathrm{B}$ by period, age and sex.

\begin{tabular}{|c|c|c|c|c|c|c|}
\hline \multirow[b]{2}{*}{ Period } & \multirow{2}{*}{ Age } & \multirow[b]{2}{*}{ Sex } & \multicolumn{2}{|c|}{ Region A } & \multicolumn{2}{|c|}{ Region B } \\
\hline & & & $\begin{array}{c}\text { Number of } \\
\text { Patients }\end{array}$ & $\begin{array}{c}\% \text { of Patients } \\
\text { with PH }\end{array}$ & $\begin{array}{c}\text { Number of } \\
\text { Patients }\end{array}$ & $\begin{array}{c}\% \text { of Patients } \\
\text { with PH }\end{array}$ \\
\hline \multirow{4}{*}{1989 to 1992} & \multirow{2}{*}{ Adult } & Male & 83 & 2.4 & 75 & 1.3 \\
\hline & & Female & 572 & 0.5 & 550 & 3.6 \\
\hline & \multirow{2}{*}{ Child } & Male & 43 & 0.0 & 62 & 0.0 \\
\hline & & Female & 85 & 2.4 & 107 & 1.9 \\
\hline \multirow{4}{*}{1993 to 1995} & \multirow{2}{*}{ Adult } & Male & 58 & 8.6 & 49 & 10.2 \\
\hline & & Female & 466 & 8.8 & 411 & 6.1 \\
\hline & \multirow{2}{*}{ Child } & Male & 21 & 0.0 & 45 & 4.4 \\
\hline & & Female & 57 & 12.3 & 98 & 6.1 \\
\hline \multirow{4}{*}{1996 to 1998} & \multirow{2}{*}{ Adult } & Male & 116 & 6.0 & 65 & 12.3 \\
\hline & & Female & 454 & 22.2 & 430 & 6.0 \\
\hline & \multirow{2}{*}{ Child } & Male & 28 & 14.3 & 48 & 6.3 \\
\hline & & Female & 54 & 24.1 & 81 & 3.7 \\
\hline \multirow{4}{*}{1999 to 2001} & \multirow{2}{*}{ Adult } & Male & 71 & 38.0 & 54 & 14.8 \\
\hline & & Female & 417 & 47.5 & 399 & 5.3 \\
\hline & \multirow{2}{*}{ Child } & Male & 37 & 29.7 & 64 & 1.6 \\
\hline & & Female & 43 & 34.9 & 71 & 2.8 \\
\hline \multirow{4}{*}{2002 to 2004} & \multirow{2}{*}{ Adult } & Male & 149 & 83.2 & 27 & 29.6 \\
\hline & & Female & 429 & 69.5 & 241 & 8.7 \\
\hline & \multirow{2}{*}{ Child } & Male & 29 & 44.8 & 33 & 12.1 \\
\hline & & Female & 144 & 23.6 & 40 & 17.5 \\
\hline
\end{tabular}

Plots of the odds of PH in Regions A and B (by sex and age) for the different three year periods are displayed in Figures 1 and 2.

\section{Region A}

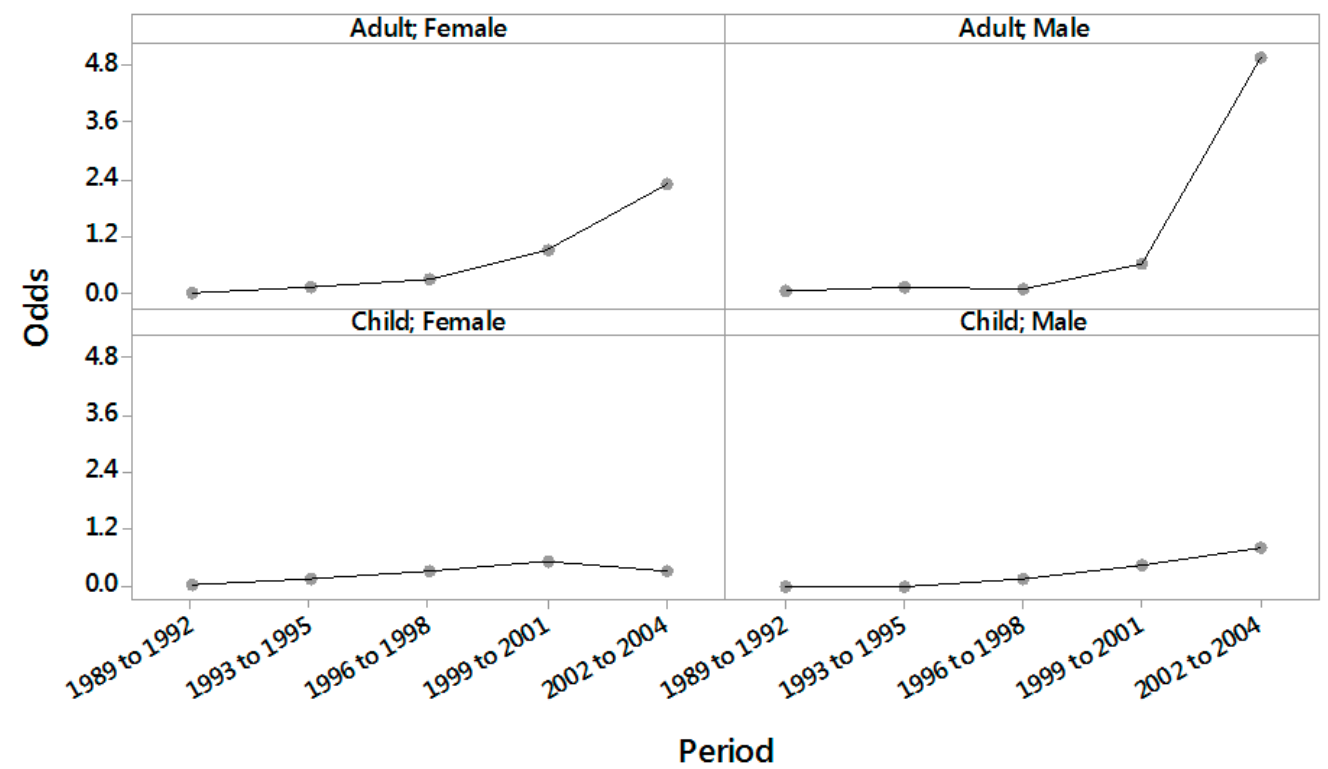

Panel variables: Age; Sex

Figure 1. Odds of PH in periods from 1989 to 1992, 1993 to 1995, 1996 to 1998, 1999 to 2001 and 2002 to 2004 for each combination of age and sex in Region A. 
Region B

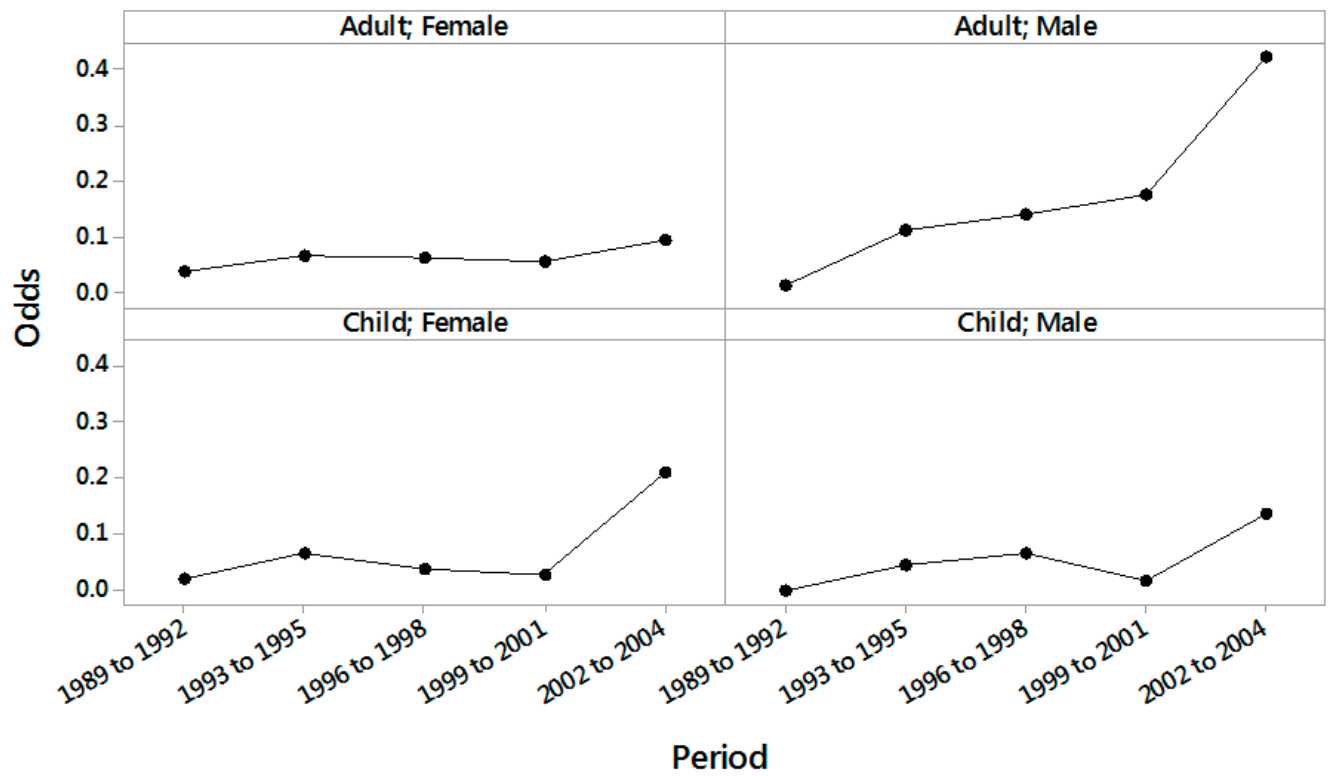

Panel variables: Age; Sex

Figure 2. Odds of PH in periods from 1989 to 1992, 1993 to 1995, 1996 to 1998, 1999 to 2001 and 2002 to 2004 for each combination of age and sex in Region B.

An increasing trend in the odds of $\mathrm{PH}$ along the triennial periods is observed in these figures, with larger slope in Region A than in Region B and for adults than for children. The estimated odds of $\mathrm{PH}$ along with $95 \%$ confidence intervals for each combination of the levels of age and sex in regions A and B for the periods 1989 to 2001 (before public disclosure) and 2002 to 2004 (after public disclosure) are displayed in Table 2.

Table 2. Odds of primary hypothyroidism (PH) and 95\% confidence intervals (CI) for the pre-public disclosure period (1989 to 2001) and odds of $\mathrm{PH}$ and 95\% confidence intervals (CI) for the post-public disclosure period (2002 to 2004).

\begin{tabular}{llccccc}
\hline \multirow{2}{*}{ Period } & \multirow{2}{*}{ Age } & \multirow{2}{*}{ Sex } & \multicolumn{2}{c}{ Region A } & \multicolumn{2}{c}{ Region B } \\
\cline { 3 - 7 } & & & Odds & CI & Odds & CI \\
\hline \multirow{3}{*}{1989 to 2001} & \multirow{2}{*}{ Child } & Female & 0.155 & $(0.098 ; 0.245)$ & 0.034 & $(0.019 ; 0.063)$ \\
& & Male & 0.066 & $(0.024 ; 0.188)$ & 0.025 & $(0.010 ; 0.066)$ \\
\cline { 3 - 7 } & \multirow{2}{*}{ Adult } & Female & 0.107 & $(0.079 ; 0.145)$ & 0.054 & $(0.044 ; 0.067)$ \\
& & Male & 0.098 & $(0.061 ; 0.158)$ & 0.078 & $(0.043 ; 0.143)$ \\
\hline \multirow{2}{*}{2002 to 2004} & \multirow{2}{*}{ Child } & Female & 0.309 & $(0.210 ; 0.454)$ & 0.212 & $(0.094 ; 0.480)$ \\
& & Male & 0.813 & $(0.391 ; 1.689)$ & 0.138 & $(0.048 ; 0.392)$ \\
\cline { 3 - 7 } & \multirow{2}{*}{ Adult } & Female & 2.275 & $(1.852 ; 2.794)$ & 0.095 & $(0.061 ; 0.149)$ \\
& & Male & 4.960 & $(3.227 ; 7.623)$ & 0.421 & $(0.184 ; 0.962)$ \\
\hline
\end{tabular}

The odds of PH for the period 1989 to 2001 (for each combination of the levels of region, sex and age) were computed as the geometric mean of the corresponding triennial odds obtained from Table 1 . The standard errors used to construct the approximate confidence intervals were computed via the log-linear functions available in the library ACD (Analysis of Categorical Data) in the software package R.

The data in Table 2 indicate that for both study periods, the odds of $\mathrm{PH}$ in Region A are greater than those in Region B, whatever the age or sex of the participants. Accordingly, for participants of the same age and sex, the odds of PH in the post-disclosure period (2002 to 2004) are greater than the corresponding ones in the pre-disclosure period (1989 to 2001). 
The odds ratio of PH between the two periods ((2002 to 2004) and (1989 to 2001)) in each region, age and sex and, as well as the corresponding odds ratio between the two regions (A/B) in each period (before and after public disclosure) for each age and sex, along with 95\% confidence intervals are presented in Tables 3 and 4. The results displayed in Table 3 show that the odds of PH in the 2002 to 2004 period are significantly greater than the corresponding odds in the 1989 to 2001 period in either region and for all combinations of the categories of age and sex. From Table 4 we may conclude that there is no significant difference between the odds of $\mathrm{PH}$ for the two regions for: (a) male children and male adults in the 1989 to 2001 period and (b) female children in the 2002 to 2004 period. Otherwise, the odds of PH in Region A are significantly greater than those in Region B.

Table 3. Odds ratios of primary hypothyroidism and 95\% confidence intervals (CI) for comparison between the post public disclosure period (2002 to 2004) and the pre public disclosure period (1989 to 2001).

\begin{tabular}{cccccccc}
\hline \multirow{2}{*}{ Age } & \multirow{2}{*}{ Sex } & \multicolumn{3}{c}{ Region A } & \multicolumn{3}{c}{ Region B } \\
\cline { 3 - 8 } & & Odds Ratio & CI & $p$ & Odds Ratio & CI & $p$ \\
\hline \multirow{2}{*}{ Child } & Female & 2.00 & $(1.10 ; 3.64)$ & 0.024 & 6.18 & $(2.23 ; 17.12)$ & $<0.001$ \\
& Male & 12.22 & $(3.43 ; 43.55)$ & $<0.001$ & 5.49 & $(1.32 ; 22.86)$ & 0.019 \\
\hline \multirow{2}{*}{ Adult } & Female & 21.24 & $(14.72 ; 30.65)$ & $<0.001$ & 1.76 & $(1.07 ; 2.88)$ & 0.026 \\
& Male & 50.67 & $(26.69 ; 96.21)$ & $<0.001$ & 5.38 & $(1.93 ; 14.98)$ & 0.001 \\
\hline
\end{tabular}

Each odds ratio in Table 3 (i.e., for each combination of the levels of sex and age) was obtained as the quotient between the corresponding odds for the period 2002 to 2004 and the odds for the period 1989 to 2001 available in Table 2. The standard errors used to construct the approximate confidence intervals were computed via the log-linear functions available in the library ACD in the software package R.

Table 4. Odds ratios of primary hypothyroidism and 95\% confidence intervals (CI) for comparison between Region A and Region B.

\begin{tabular}{cccccccc}
\hline \multirow{2}{*}{ Age } & \multirow{2}{*}{ Sex } & \multicolumn{3}{c}{ 1989 to 2001 } & \multicolumn{3}{c}{ 2002 to 2004 } \\
\cline { 3 - 8 } & & Odds Ratio & CI & $p$ & Odds Ratio & CI & $p$ \\
\hline \multirow{2}{*}{ Child } & Female & 4.54 & $(2.10 ; 9.66)$ & $<0.001$ & 1.46 & $(0.59 ; 3.59)$ & 0.413 \\
& Male & 2.65 & $(0.64 ; 10.96)$ & 0.179 & 5.89 & $(1.64 ; 21.10)$ & 0.007 \\
\hline \multirow{2}{*}{ Adult } & Female & 1.97 & $(1.36 ; 2.85)$ & $<0.001$ & 23.83 & $(14.56 ; 39.00)$ & $<0.001$ \\
& Male & 1.25 & $(0.58 ; 2.70)$ & 0.570 & 11.78 & $(4.64 ; 29.89)$ & $<0.001$ \\
\hline
\end{tabular}

Each odds ratio in Table 4 (i.e., for each combination of the levels of sex and age) was obtained as the quotient between the corresponding odds for Region A and the odds for Region B available in Table 2. The standard errors used to construct the approximate confidence intervals were computed via the log-linear functions available in the library ACD in the software package R.

\section{Discussion}

Our results indicated that the odds of $\mathrm{PH}$ for residents in the vicinity of petrochemical plants that manufacture polyethylene, polypropylene and many other products (Region A) are larger than those for residents in a control region (Region B) and have an increasing trend over the study period (1989 to 2004) for both children and adults of either sex. Furthermore, the results suggested that the odds of PH increase drastically after public disclosure of an abnormal frequency of the disease. We conjecture that such environmental contaminants might be a cause of the unusual number of thyroid pathology detected.

Landrigan et al. [26] showed that environmental pollutants, chemicals, solid waste and pharmaceuticals have a negative impact on the developing immune system of children and this may justify the increased odds of PH in Region A reported for children since all the children diagnosed with PH were also diagnosed with CAT.

Radetti et al. [27], in a multicentre study, investigated the outcome of euthyroid children with HT and showed that $64.8 \%$ of them remained euthyroid, $9.5 \%$ progressed to subclinical hypothyroidism 
and $25.7 \%$ to overt hypothyroidism after 5 years. Although we are not evaluating prevalence, the larger odds of $\mathrm{PH}$ observed for males suggest that the prevalence of $\mathrm{PH}$ in Region A is greater than those in Vanderpump and Tunbridge [28] who reported a prevalence of $2 \%$ in an adult female population as opposed to $0.2 \%$ in a male population. In fact, the prevalence of $\mathrm{PH}$ in different adult populations are reported in many studies [7,28-32] and range from $0.1 \%$ to $2.0 \%$, but not much is known about the corresponding prevalence in children.

Benvenga et al. [33] have demonstrated that in most industrialized countries, autoimmune disorders including chronic lymphocytic thyroiditis (CLT) are increasing. This increase parallels the one regarding differentiated thyroid cancer and these thyroid diseases could be related by certain environmental factors, such as polluting substances acting as endocrine disrupting chemicals. Arena et al. [34] concluded that the petrochemical complex-related pollutions in an environmental factor involved in the development of CLT and, likely, in the CLT association with thyroid neoplasms.

The concentration of iodine has been considered a modulating factor for thyroid autoimmunity [35]. Zak et al. [36], for example, observed a decrease in the frequency of new cases of CLT from $30 \%$ in 1999 to $10 \%$ in 2004, probably because of the introduction of mandatory iodine prophylaxis in Poland in 1997. Langer et al. [37], on the other hand, found that the levels of urinary iodine were within normal limits in the residents of a polluted area. A populational study conducted in China showed that an augmented ingestion of iodine may be considered as a risk factor for the progression of $\mathrm{PH}$ [38]. Although hypothyroidism appears to be common among the adult population of Isfahan, Iran, its high prevalence is probably due to autoimmunity, with no correlation to iodine intake [39].

The major cause of $\mathrm{PH}$ in iodine sufficient regions is CAT [10] and although the presence of A-TPO defines the diagnosis of CAT, all the 1078 children and adults (905 in Region A and 173 in Region B) with PH evaluated in this study (Table 1) presented A-Tg and A-TPO positive antibodies; also, the sonographic scans of their thyroid glands showed heterogeneous texture and marked hypoechogenicity.

In Brazil, Rosario et al. [40] have shown that not only the presence of A-TPO antibodies, but also that ultrasonographic aspects of CAT are associated with a greater risk of progression to $\mathrm{PH}$. Marcocci et al. [41] concluded that patients with CAT and hypoecogenicity in thyroid ultrassonographic exams have a greater probability to progress to PH. In fact, Huber et al. [42] showed that the annual incidence of $\mathrm{PH}$ in the presence of antithyroid antibodies is $11.4 \%$.

A few Brazilian studies [22,43,44] have shown iodine sufficiency in the general population and a study conducted in Region A [21] also came to a similar conclusion. The average urine iodine was $26.5 \mu \mathrm{g} / \mathrm{dL}$ (reference values ranging from 10-30 $\mu \mathrm{g} / \mathrm{dL}$ ) in Region A and iodine concentration in table salt consumed in the same region was $31.9 \mathrm{mg} / \mathrm{kg}$ which lies within the acceptable limits of $20-60 \mathrm{mg} / \mathrm{kg}$, suggesting that environmental factors are the most plausible cause of the reported results of our study.

According to Brent [16], although approximately 70\% of the risk for developing autoimmune thyroid disease is attributable to genetic background, environmental triggers are thought to play a role in this process for susceptible individuals.

Sgarbi and Maciel [45] also reported that the interaction between genetic susceptibility and environmental factors appears to be of fundamental importance to initiate the process of thyroid autoimmunity. No significant differences between the average concentrations of particulate matter $\left(\mathrm{PM}_{10}\right)$ and ozone $\left(\mathrm{O}_{3}\right)$ in the two regions considered in this study were identified.

In our study, $\mathrm{PH}$ and CAT were diagnosed in residents coming from different families including married couples thus circumventing the influence of genetic factors. In fact, our conjectures regarding the high prevalence of CAT in Region A was corroborated in a study sponsored by the Epidemiological Surveillance Center (ESC) of the Department of Health of the State of São Paulo [21].

Certain pharmacologic agents like interferon, amiodarone, iodine and lithium may also cause autoimmune thyroid diseases and PH in predisposed individuals [46]. Patients taking these medications 
were excluded from our study; this may be considered as further evidence that the vicinity to the petrochemical complex is the most probable cause of the abnormal cases of $\mathrm{PH}$ detected in our study.

Finally, we observed that the odds of $\mathrm{PH}$ in children and adults of both sexes in Region A increased drastically after the public health authorities were notified in 2002. This observation suggests that awareness of the population contributed to new diagnoses of $\mathrm{PH}$ and before that the signs and symptoms of hypothyroidism were not taken into account, mainly in children with learning difficulties, memory problem, attention and concentration problem and growth deficits.

The patients with clinical and laboratory $\mathrm{PH}$ were treated with sodium levothyroxine and remain with normal thyroid function; however the $\mathrm{A}-\mathrm{Tg}$ and $\mathrm{A}-\mathrm{TPO}$ of these patients are still above normality. This suggests that there is no treatment for CAT, thus opening a new field for research.

Given the observational nature of our study, it is subject to many limitations, among which we mention the lack of objective control of confounding factors like social and educational status of the participants or quantification of actual exposure to specific organochlorinated products such as pesticides and solvents. A follow up collaborative study with the Laboratory of Atmospheric Pollution of the University of São Paulo Medical School is already being conducted.

\section{Conclusions}

We detected an increasing trend in the odds of $\mathrm{PH}$ along the observation period with greater slope in the study region than in the control region. We also noted that the odds of $\mathrm{PH}$ in the post-disclosure period (2002 to 2004) are greater than the corresponding ones in the pre-disclosure period (1989 to 2001). After the 2002 public disclosure of this increase in the frequency of $\mathrm{PH}$, the information disseminated by health service professionals and teachers in schools contributed to the awareness of the problem leading to an early diagnosis, especially in children. Given the asymptomatic characteristic of the disease in its initial development individuals and the risk of its complications, our suggestion is that the thyroid gland must be evaluated in employees of chemical plants as well as in residents living around such industrial areas.

Acknowledgments: The authors are grateful to Antonio Achur (Fleming Laboratory) for the laboratory examinations, to Edson R. Iglezias image diagnosis (DISA) for the Image examinations as well as to Walter Bloise, Rui M. B. Maciel, Éder Quintão and Paulo H. N. Saldiva, for their support and collaboration. We also want to thank our patients for all the information and understanding. This research received partial financial support from Conselho Nacional de Desenvolvimento Científico e Tecnológico (CNPq, grant \# 304126/2015-2), Brazil and Fundação de Amparo à Pesquisa do Estado de São Paulo (FAPESP, grant \# 2013/21728-2), Brazil.

Author Contributions: Maria Angela Zaccarelli-Marino participated in the design of the study, acquisition of data, interpretation of the results, draft of the manuscript and critically revised the manuscript. Carmen Diva Saldiva André participated in the statistical analysis, interpretation of the results and critically revised the manuscript. Julio M. Singer participated in the statistical analysis, interpretation of the results and critically revised the manuscript. All authors have read and approved the final manuscript.

Conflicts of Interest: The authors declare no conflict of interest.

\section{References}

1. Gist, G.L.; Burg, J.R. Trichloroethylene: A review of the literature from a health effects perspective. Toxicol. Ind. Health 1995, 11, 253-307. [CrossRef] [PubMed]

2. Davis, J.D.; Tremont, G. Neuropsychiatric aspects of hypothyroidism and treatment reversibility. Minerva Endocrinol. 2007, 32, 49-65. [PubMed]

3. Brent, G.A. The molecular basis of thyroid hormone action. N. Engl. J. Med. 1994, 331, 847-853. [PubMed]

4. Garber, J.R.; Cobin, R.H.; Gharib, H.; Hennessey, J.V.; Klein, I.; Mechanick, J.I.; Pessah-Pollack, R.; Singer, P.A.; Wolber, K. Clinical practice guidelines for hypothyroidism in adults: Cosponsored by the American Association of Clinical Endocrinologists and the American Thyroid Association. Thyroid 2012, 22, 1200-1235. [CrossRef] [PubMed]

5. Lazarus, J.H. Thyroid hormones and cognitive function. Expert Rev. Endocrinol. Metab. 2012, 7, 365-367. [CrossRef] 
6. Weber, G.; Vigone, M.C.; Stroppa, L.; Chiumello, G. Thyroid function and puberty. J. Pediatr. Endocrinol. Metab. 2003, 16, 253-257. [PubMed]

7. Vanderpump, M.P.J.; Tunbridge, W.M.G.; French, J.M.; Appleton, D.; Bates, D.; Clark, F.; Grimley, E.J.; Hasan, D.M.; Rodgers, H.; Tunbridge, F.; et al. The incidence of thyroid disorders in the community: A twenty-year follow-up of the Whickham Survey. Clin. Endocrinol. 1995, 43, 55-68. [CrossRef]

8. Wang, C.; Crapo, L.M. The epidemiology of thyroid disease and implications for screening. Endocrinol. Metab. Clin. N. Am. 1997, 26, 189-218. [CrossRef]

9. Tunbridge, W.M.G.; Vanderpump, M.P.J. Population screening for autoimmune thyroid disease. Endocrinol. Metab. Clin. N. Am. 2000, 29, 239-253. [CrossRef]

10. Dayan, C.M.; Daniels, G.H. Chronic autoimmune thyroiditis. N. Engl. J. Med. 1996, 335, 99-107. [CrossRef] [PubMed]

11. Benvenga, S.; Trimarchi, F. Changed presentation of Hashimoto's Thyroiditis in north-eastern Sicily and Calabria (southern Italy) based on a 31-year experience. Thyroid 2008, 18, 429-441. [CrossRef] [PubMed]

12. Rizzo, M.; Rossi, R.T.; Bonaffini, O.; Scisca, C.; Altavilla, G.; Calbo, L.; Rosano, A.; Sindoni, A.; Trimarchi, F.; Benvenga, S. Increased annual frequency of Hashimoto's Thyroiditis between years 1988 and 2007 at a cytological unit of Sicily. Ann. Endocrinol. 2010, 71, 525-534. [CrossRef] [PubMed]

13. Gilbert, K.M.; Griffin, J.M.; Pumford, N.R. Trichloroethylene activates CD4+ T cells: Potential role in an autoimmune response. Drug Metab. Rev. 1999, 31, 901-916. [CrossRef] [PubMed]

14. Selgrade, M.K. Immunotoxicity: The risk is real. Toxicol. Sci. 2007, 100, 328-332. [CrossRef] [PubMed]

15. Bahn, A.K.; Mills, J.L.; Synder, P.J.; Gann, P.H.; Houten, L.; Bialik, O.; Hollmann, L.; Utiger, R.D. Hypothyroidism in workers exposed to polybrominated biphenyls. N. Engl. J. Med. 1980, 302, 31-33. [CrossRef] [PubMed]

16. Brent, G.A. Environmental exposures and autoimmune thyroid disease. Thyroid 2010, 20, 755-761. [CrossRef] [PubMed]

17. Burek, C.L.; Talor, M.V. Environmental triggers of autoimmune thyroiditis. J. Autoimmun. 2009, 33, $183-189$. [CrossRef] [PubMed]

18. Yang, C.Y.; Chiu, H.F.; Tsai, S.S.; Chang, C.C.; Chuang, H.Y. Increased risk of preterm delivery in areas with cancer mortality problems from petrochemical complex. Environ. Res. 2002, 69, 195-200. [CrossRef]

19. Neuberger, J.S.; Ward-Smith, P.; Morantz, R.A.; Tian, C.; Schmelzie, K.H.; Mayo, M.S.; Chin, T.D. Brain cancer in a residential area bordering on an oil refinery. Neuroepidemiology 2003, 22, 46-56. [CrossRef] [PubMed]

20. Zaccarelli-Marino, M.A. Chronic autoimmune thyroiditis in industrial areas in Brazil: A 15 year survey. J. Clin. Immun. 2012, 32, 1012-1018. [CrossRef] [PubMed]

21. Freitas, C.U.; Campos, R.A.G.; Silva, M.A.F.R.; Panachão, M.R.I.; Moraes, J.C.; Waissmann, W.; Chacra, A.R.; Maeda, M.Y.S.; Rodrigues, R.S.M.; Belchor, L.G.; et al. Can living in the surroundings of a petrochemical complex be a risk factor for autoimmune thyroid disease? Environ. Res. 2010, 110, 112-117. [CrossRef] [PubMed]

22. Esteves, R.Z.; Kasamatsu, T.S.; Kunii, I.S.; Furuzawa, G.K.; Vieira, J.G.H.; Maciel, R.M.B. Development of a semi-automated method of measuring urinary iodine and its application in epidemiological studies in Brazilian schoolchildren. Braz. Arch. Endocrinol. Metab. 2007, 51, 1477-1484. [CrossRef]

23. Zaccarelli-Marino, M.A.; Martins, L.C.; Esteves, R.Z.; Kasamatsu, T.S.; Maciel, R.M.B. Urinary iodine in patients with auto-immune thyroid disorders in Santo André, SP, is comparable to normal controls and has been steady for the last 10 years. Braz. Arch. Endocrinol. Metab. 2009, 53, 55-63.

24. Agresti, A. Categorical Data Analysis, 3rd ed.; Wiley: Hoboken, NJ, USA, 2012; pp. 339-376.

25. R Core Team. R: A Language and Environment for Statistical Computing; R Foundation for Statiscal Computing: Vienna, Austria, 2016.

26. Landrigan, P.G. Children as a vulnerable population. Int. J. Occup. Med. Environ. Health 2004, 17, $175-177$. [CrossRef] [PubMed]

27. Radetti, G.; Gottardi, E.; Bona, G.; Corrias, A.; Salardi, S.; Loche, S. Study group for thyroid diseases of the Italian society for pediatric endocrinology and diabetes (SIEDP/ISPED). The natural history of euthyroid Hashimoto's Thyroiditis in children. J. Pediatr. 2006, 149, 827-832. [CrossRef] [PubMed]

28. Vanderpump, M.P.J.; Tunbridge, W.M.G. The epidemiology of thyroid diseases. In Werner and Ingbar's the Thyroid: A Fundamental and Clinical Text; Braverman, L.E., Utiger, R.D., Eds.; Lippincott Williams and Wilkins: Philadelphia, PA, USA, 2000; pp. 467-473. 
29. Tunbridge, W.M.G.; Evered, D.C.; Hall, R.; Appleton, D.; Brewis, M.; Clark, F.; Grimley, E.J.; Young, E.; Bird, T.; Smith, A. The spectrum of thyroid disease in a community: The Whickham Survey. Clin. Endocrinol. 1997, 7, 481-493. [CrossRef]

30. Canaris, G.J.; Manowitz, N.R.; Mayor, G.; Ridgway, E.C. The Colorado thyroid disease prevalence study. Arch. Int. Med. 2000, 160, 526-534. [CrossRef]

31. Aoki, Y.; Belin, R.M.; Clickner, R.; Jeffries, R.; Phillips, L.; Mahaffey, K.R. Serum TSH and total T4 in the United States population and their association with participant characteristics: National Health and Nutrition Examination Survey (NHANES 1999-2002). Thyroid 2007, 17, 1211-1223. [CrossRef] [PubMed]

32. Hollowell, J.G.; Staehling, N.W.; Flanders, D.F.W.; Hannon, H.W.; Gunter, E.W.; Spencer, C.A.; Braverman, L.E.; Serum, T.S.H. T4, and thyroid antibodies in the United States population (1988 to 1994): National Health and Nutrition Examination Survey (NHANES III). J. Clin. Endocrinol. Metab. 2002, 87, 489-499. [CrossRef] [PubMed]

33. Benvenga, S.; Antonelli, A.; Vita, R. Thyroid nodules and thyroid autoimmunity in the context of environmental pollution. Rev. Endocrinol. Metab. Disord. 2015, 16, 319-340. [CrossRef] [PubMed]

34. Arena, S.; Latina, A.; Baratta, R.; Burgio, G.; Gullo, D.; Benvenga, S. Chronic lymphocytic thyroiditis: Could it be influenced by a petrochemical complex? Data from a cytological study in south-eastern Sicily. Eur. J. Endocrinol. 2015, 172, 383-389. [CrossRef] [PubMed]

35. Prummel, M.F.; Strieder, T.; Wiersinga, W.M. The environment and autoimmune thyroid diseases. Eur. J. Endocrinol. 2004, 150, 605-618. [CrossRef] [PubMed]

36. Zak, T.; Noczynska, A.; Wasikowa, R.; Zaleska-Dorobisz, U.; Golenko, A. Chronic autoimmune thyroid disease in children and adolescents in the years 1999-2004 in Lower Silesia, Poland. Hormones 2005, 4, 45-48. [PubMed]

37. Langer, P.; Tajtáková, M.; Fodor, G.; Kocan, A.; Bohov, P.; Michálek, J.; Kreze, A. Increased thyroid volume and prevalence of thyroid disorders in an area heavily polluted by polychlorinated biphenyls. Eur. J. Endocrinol. 1998, 139, 402-409. [CrossRef] [PubMed]

38. Li, Y.; Teng, D.; Shan, Z.; Teng, X.; Guan, H.; Yu, X.; Fan, C.; Chong, W.; Yang, F.; Dai, H.; et al. Antithyroperoxidase and antithyroglobulin antibodies in a five-years follow-up survey of populations with different iodine intakes. J. Clin. Endocrinol. Metab. 2008, 93, 1751-1757. [CrossRef] [PubMed]

39. Aminorroaya, A.; Janghorbani, M.; Amini, M.; Hovsepian, S.; Tabatabaei, A.; Fallahm, Z. The prevalence of thyroid dysfunction in an iodine-sufficient area in Iran. Arch. Iran. 2009, 12, 262-270.

40. Rosario, P.W.; Bessa, B.; Valadao, M.M.; Purisch, S. Natural history of mild subclinical hypothyroidism: Prognostic value of ultrasound. Thyroid 2009, 19, 9-12. [CrossRef] [PubMed]

41. Marcocci, C.; Vitti, P.; Cetani, F.; Catalano, F.; Concetti, R.; Pinchera, A. Thyroid ultrasonography helps to identify patients with diffuse lymphocytic thyroiditis who are prone to develop hypothyroidism. J. Clin. Endocrinol. Metab. 1991, 72, 209-213. [CrossRef] [PubMed]

42. Huber, G.; Staub, J.J.; Meier, C.; Mitrache, C.; Guglielmetti, M.; Huber, P.; Braverman, L.E. Prospective study of the spontaneous course of subclinical hypothyroidism: Prognostic value of thyrotropin, thyroid reserve, and thyroid antibodies. J. Clin. Endocrinol. Metab. 2002, 87, 3221-3226. [CrossRef] [PubMed]

43. Sgarbi, J.A.; Kasamatsu, T.S.; Matsumura, L.K.; Maciel, R.M.B. Parity is not related to autoimmune thyroid disease in a population-based study of Japanese-Brazilian. Thyroid 2010, 20, 1151-1156. [CrossRef] [PubMed]

44. Sgarbi, J.A.; Matsumura, L.K.; Kasamatsu, T.S.; Ferreira, S.R.; Maciel, R.M.B. Subclinical thryroid dysfunctions are independent risk factors for mortality in a 7.5-year follow-up: The Japanese-Brazilian thyroid study. Eur. J. Endocrinol. 2010, 162, 569-577. [CrossRef] [PubMed]

45. Sgarbi, J.A.; Maciel, R.M.B. Pathogenesis of autoimmune thyroid diseases. Braz. Arch. Endocrinol. Metab. 2009, 53, 5-14. [CrossRef]

46. Vanderpump, M.P.J.; Tunbridge, W.M.G. The effects of drugs on endocrine function. Clin. Endocrinol. 1993, 39, 389-397. [CrossRef]

(c) 2016 by the authors; licensee MDPI, Basel, Switzerland. This article is an open access article distributed under the terms and conditions of the Creative Commons Attribution (CC-BY) license (http://creativecommons.org/licenses/by/4.0/). 